\title{
Cardiac Biomarkers: What Is and What Can Be
}

\author{
Rachel Jacob ${ }^{1}$ Mahmood Khan² \\ ${ }^{1}$ Department of Biochemistry, Nizam's Institute of Medical \\ Sciences, Punjagutta, Hyderabad, Telangana, India \\ ${ }^{2}$ Department of Emergency Medicine, Department of Physiology \\ and Cell Biology, Cardiovascular Stem Cell Therapeutics Lab, Davis \\ Heart and Lung Research Institute, The Ohio State University, \\ Columbus, Ohio, United States
}

Indian J Cardiovasc Dis Women-WINCARS 2018;3:240-244

\begin{abstract}
Address for correspondence Rachel Jacob, PhD, Department of Biochemistry, Nizam's Institute of Medical Sciences, Punjagutta, Hyderabad 500082, Telangana, India (e-mail: rachel.jacob@gmail.com).
\end{abstract}

\begin{abstract}
Keywords

- cardiac biomarkers

- cardiovascular disease

- microRNA

Cardiac biomarkers are of great importance in the timely, accurate diagnosis and management of acute coronary syndrome as well as the prognosis. Diagnosis in the golden period is of utmost importance to institute therapy at the earliest and possibly reverse the myocardial damage. Cardiac biomarkers are also a powerful tool for triaging. Among the many biomarkers, the earliest examined were the myocardial enzymes, several myocardial proteins, peptides, and many other molecules. The latest addition to the repertoire is the microRNAs, which are stable molecules detectable in circulation. About four groups are found to be involved in regulation of circulatory system, and some show promise as specific and early markers of acute coronary syndrome and cardiac dysfunction. As in other fields of medicine, personalized precise treatment may be possible with the use of microRNAs. However, as of now, a multipronged approach, involving different markers of which troponins are necessary, seems to be the best way forward.
\end{abstract}

\section{Introduction}

Cardiac biomarkers are central to the new definition of acute myocardial infarction (AMI) as defined by the American College of Cardiology and the European society of Cardiology. ${ }^{1} \mathrm{~A}$ biomarker is "a characteristic that is objectively measured and quantified as an indicator of normal biological processes, pathogenic processes or pharmacological response to a therapeutic intervention." Research in this area has broadened our knowledge base, shedding more light on the underlying pathologic mechanisms occurring in patients.

Several cardiac markers have been used in the diagnosis and management of cardiovascular (CV) disease. However, a lack of sensitivity and specificity to cardiac muscle necrosis continues to be the need to look for newer specific molecules. In the past decade many newer molecules have been tried and tested to improve the specificity to $\mathrm{CV}$ diseases, be it acute coronary syndrome (ACS) or heart failure (HF). Cardiac biomarkers are of great importance in the timely, accurate diagnosis and management of ACS as well as the prognosis. Diagnosis in the golden period is of utmost importance to institute therapy at the earliest and possibly reverse the myocardial damage. Cardiac biomarkers are also a powerful tool for triaging. Among the many biomarkers, the earliest examined were the myocardial enzymes, several myocardial proteins, peptides, and many other molecules. In this review, we will look at the spectra of cardiac biomarkers and the potential use and future of many of these molecules.

All enzymes-as early as 1954, aspartate amino transferase (AST), followed by lactate dehydrogenase (LDH) in 1955 and creatine phosphokinase (CPK) or creatine kinase (CK) in 1960-from the myocardium were used to diagnose ACS. However, the enzyme assays soon were overtaken by other smaller molecules that were detected much earlier to actual myocardial necrosis and are now mostly obsolete. The isoforms of CK were separated by electrophoresis in 1972 and are very useful in early detection.

Classification of cardiac biomarkers is the following:

I. Biomarkers of myocardial injury:

- Biomarkers of myocardial necrosis: CK-MB fraction, myoglobin, cardiac troponins

- Biomarkers of myocardial ischemia: Ischemia-modified albumin (IMA), heart-type fatty acid-binding protein (H-FABP) 
II. Biomarkers of hemodynamic stress: Natriuretic peptides (NPs): atrial natriuretic peptide (ANP), N-terminal proBNP (NT-proBNP), B-type natriuretic peptide (BNP)

III. Inflammatory and prognostic markers: hs C-reactive protein (CRP), sCD40L, homocysteine

\section{Biomarkers of Myocardial Necrosis}

\section{Creatine Kinase and Creatine Kinase-MB}

The earliest biomarker to increase is the muscle enzyme, $\mathrm{CK}$ or $\mathrm{CPK}$, which is present in the cytosol of the myocytes and predominantly released into the bloodstream from the necrosed myocardium. The CK-MB fraction being more specific to the myocardium quickly replaced the CK and is considered the gold standard. CK-MB forms nearly $30 \%$ of CK in the myocardium, and a rise of $>5 \%$ of the total CK activity suggests damage to the cardiac muscle. CK-MB appears in the bloodstream 4 to 6 hours after onset of chest pain and peaks between 10 and 12 hours after the myocardial infarction (MI). It was the best marker for early detection for many decades. The best time for detection is between 6 and 48 hours beyond which it is cleared; hence in cases of late arrivals, normal CK-MB could present an incorrect picture. Also, a trend detected in serial measurements provides better information than single measurements. Therefore, $\mathrm{MI}$ is unlikely if $\mathrm{CK}$ is not increased in patients with chest pain and a failure of elevated CK levels to fall indicates that there is an extension of the infarct. It is shown that in high-risk patients, even minor elevations have important prognostic implications. ${ }^{2}$

The relative index is a very useful index to helps differentiate between $\mathrm{CK}$ from the myocardium, skeletal muscle, or from neural damage. It is calculated as:

$$
\text { Relative index }=\mathrm{CK}-\mathrm{MB} / \text { Total } \mathrm{CK} \times 100
$$

A relative index of $>2.5$ to 3 indicates very likely heart damage, lower index suggesting skeletal muscle damage. ${ }^{3}$

Rather than the enzyme activity of CK and CK-MB, the CK mass estimated is found to be of better diagnostic value, but the costs being considerable is not easily available. Because there is a lag period for the elevation of CK-MB levels after onset of chest pain, other potential markers such as myoglobin and troponins were pursued.

\section{Cardiac Troponins}

Troponins are the contractile proteins in muscle cells, which present very early in the bloodstream, 3 to 9 hours post infarct. Cardiac-specific isoforms have been identified, and among the three troponins in the contractile component of the myocardium, troponin-I and troponin-T are widely used. ${ }^{4}$ Both are highly specific and sensitive for myocardial damage, though troponin- $\mathrm{T}$ is known to increase in unstable angina. Cardiac troponin (cTn) I, increases in 4 to 6 hours, peaks at 12 hours, and returns to basal levels in 3 to 10 days, whereas troponin-T stays elevated for 12 to 48 hours and falls to normal in 10 days. ${ }^{5} \mathrm{MI}$ is highly unlikely if troponins are not elevated, and a point-of-care testing device is used considerably at the bedside to exclude cardiac damage in patients with chest pain. cTn testing is an essential component of the diagnostic workup and management of ACS.
The introduction of a high-sensitivity troponin (hs-Trop) assay has been very useful in patients with non-ST-elevation myocardial infarction (NSTEMI), which allows diagnosis by a single blood test, thus permitting early treatment than otherwise might be advised. Some studies have concluded that a single hsTnT level $\leq 6 \mathrm{ng} / \mathrm{L}$ indicated a very low risk of AMI, whereas serial levels exceeding $19 \mathrm{ng} / \mathrm{L}$ identified patients with < $1 \%$ risk of adverse cardiac events., In highly suspected cases of AMI, high sensitive troponin assay can be used effectively to "rule out" in about $60 \%$ cases when the value remains low at 0 hour with no change after 1 hour. When it is elevated at 0 hour with a large increase at 1 hour, it is a "rule-in" and is diagnostic of an AMI. ${ }^{8}$

The hsTn assays are also of value in prognostication in patients with acute heart failure (AHF) if seen in detectable values, as seen in a study by Xue et al. ${ }^{7}$ The patients who at discharge had a level of hsTnI $>23.25 \mathrm{ng} / \mathrm{L}$ had increased risk of readmission and mortality, and studies with hsTnT have also shown similar prognostic value. Thus tropinins play a significant role in assessment of cardiac dysfunction.

\section{Myoglobin}

The small heme protein that assists in oxygen transport in all muscle tissues, is released within 1 hour and rises more rapidly than cTn or CK-MB, peaks in nearly 8 to 10 hours, and returns to normal within 24 hours. Thus, it is a sensitive early indicator of cardiac damage, and though nonspecific to the myocardium, it has found use as an excellent negative predictor of myocardial injury. If there is no rise seen in serum myoglobin levels in two samples analyzed 2 to 4 hours apart, it virtually rules out AMI (-Table $\mathbf{1}$ ).

\section{Markers of Myocardial Ischemia Ischemia-Modified Albumin}

When the circulating serum albumin comes into contact with the ischemic heart tissue, a novel marker of ischemia is produced by the structural modification of albumin at the $\mathrm{N}$-terminal end, which is used for the estimation. IMA rises within 6 hours of an infarct and remains elevated for 12 hours. The drawback with IMA is that it is induced by conditions such as extracellular hypoxia, acidosis, etc. ${ }^{9}$ Nevertheless, in 2010, the Food and Drug Administration (FDA) has included it in combination with electrocardiogram (ECG) and the cTnI, as together $95 \%$ sensitivity is achieved for ACS.

\section{Heart-type Fatty Acid-Binding Protein}

It is a very stable low-molecular-weight (14-15 $\mathrm{kDa})$ protein present in the myocardial cytoplasm. These are involved in the transport of fatty acids from the cell membrane to the mitochondria for oxidation. Due to their small size, they are easily diffused through the interstitial space and appear in 1 to 3 hours after onset, peak levels are achieved in 6 hours, and return to normal in 24 hours. Use of H-FABP may improve diagnostic ability, but the presence of easily available specific markers such as troponins has made it of an additive value only. ${ }^{10}$

\section{Biomarkers of Hemodynamic Stress}

Natriuretic peptides are a group of structurally similar but genetically distinct molecules that are involved in 
Table 1 Different biomarkers and their concentrations with relation to time after an AMI6

\begin{tabular}{|c|c|c|c|c|c|c|c|c|c|c|c|}
\hline Biomarker & $\begin{array}{l}6 \\
\text { hours }\end{array}$ & $\begin{array}{l}12 \\
\text { hours }\end{array}$ & $\begin{array}{l}19-21 \\
\text { hours }\end{array}$ & $\begin{array}{l}24 \text { hours } \\
\text { (1 day) }\end{array}$ & $\begin{array}{l}48 \text { hours } \\
\text { (2 days) }\end{array}$ & 3 days & 4 days & 5 days & 6 days & 7 days & $\begin{array}{l}14 \\
\text { days }\end{array}$ \\
\hline Myoglobin & $\begin{array}{l}20 \mathrm{x} \\
\text { URR }\end{array}$ & Normal & & & & & & & & & \\
\hline CK-MB & $\begin{array}{l}20 x \\
\text { URR }\end{array}$ & $\begin{array}{l}40 x \\
\text { URR }\end{array}$ & $\begin{array}{l}30 \mathrm{x} \\
\text { URR }\end{array}$ & $20 \times$ URR & Normal & & & & & & \\
\hline $\begin{array}{l}\text { Creatine } \\
\text { kinase }\end{array}$ & $\begin{array}{l}3 x \\
\text { URR }\end{array}$ & $\begin{array}{l}8 x \\
\text { URR }\end{array}$ & $8 \times$ URR & 8x URR & $5 \times$ URR & Normal & & & & & \\
\hline Troponin I & $\begin{array}{l}50 x \\
\text { URR }\end{array}$ & $\begin{array}{l}98 x \\
\text { URR }\end{array}$ & $\begin{array}{l}70 x \\
\text { URR }\end{array}$ & $50 \times$ URR & $35 \times$ URR & $38 \times$ URR & $\begin{array}{l}35 \mathrm{x} \\
\text { URR }\end{array}$ & $\begin{array}{l}30 x \\
\text { URR }\end{array}$ & $\begin{array}{l}20 x \\
\text { URR }\end{array}$ & $\begin{array}{l}\text { Nor- } \\
\text { mal }\end{array}$ & \\
\hline Troponin T & $\begin{array}{l}50 x \\
\text { URR }\end{array}$ & $\begin{array}{l}98 x \\
\text { URR }\end{array}$ & $\begin{array}{l}80 x \\
\text { URR }\end{array}$ & $70 \times$ URR & $48 \times$ URR & $45 \times$ URR & $\begin{array}{l}40 \mathrm{x} \\
\text { URR }\end{array}$ & $\begin{array}{l}35 x \\
\text { URR }\end{array}$ & $\begin{array}{l}25 x \\
\text { URR }\end{array}$ & $\begin{array}{l}15 x \\
\text { URR }\end{array}$ & Normal \\
\hline
\end{tabular}

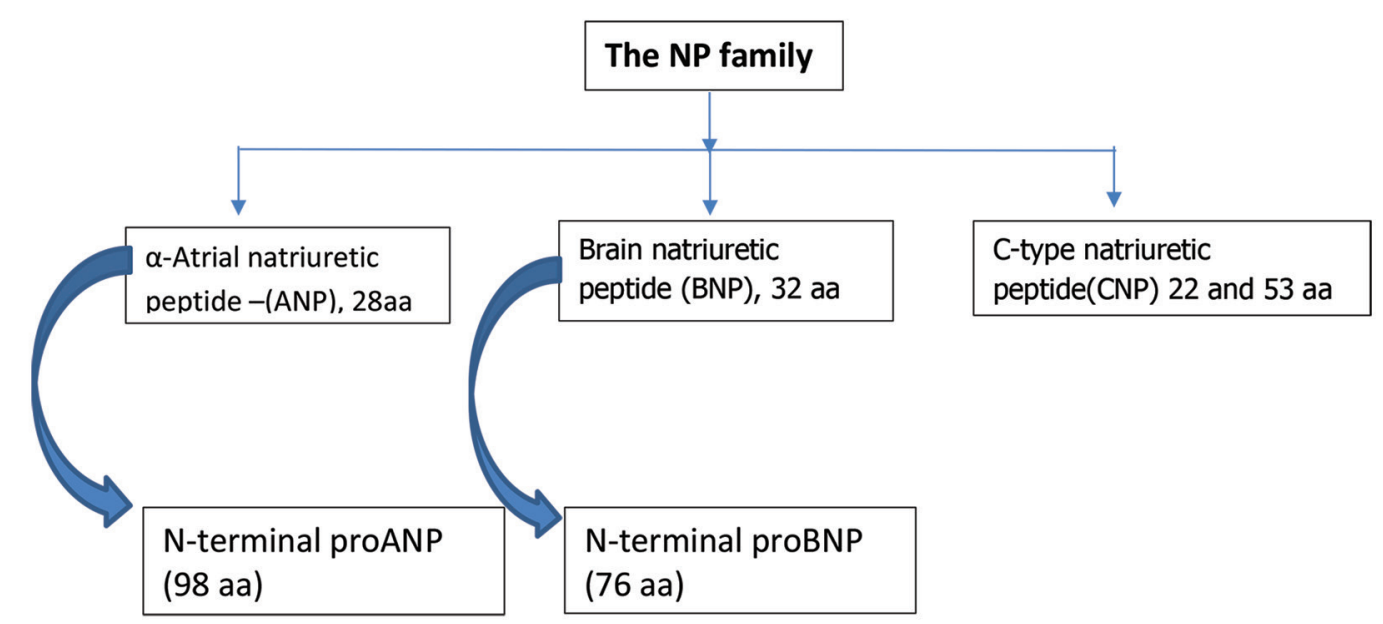

Fig. 1 Different biomarkers and their concentrations with relation to time after an AMI. ${ }^{6} \mathrm{CK}$, creatine kinase; CK-MB, creatine kinase-MB; LDH, lactate dehydrogenase; ULRR, upper limit of the reference range.

the sodium and water excretion, thus lowering of blood pressure. The NP family includes $\alpha$-ANP, 28 amino acids; BNP, 32 amino acids; and C-type natriuretic peptide (CNP), 22 and 53 amino acids (-Fig. 1).

The increased blood flow into the ventricles/pressure creates a stretch in the ventricular wall, which is an inducer of transcription for NP. Furthermore, it modulates diuresis, natriuresis, vasodilation, inhibition of renin and aldosterone, and helps reduce the blood pressure. The prohormone (proBNP) is cleaved to BNP and NT-proBNP, where NT-proBNP is the inert inactive molecule, both of which can be assayed. The half-life of BNP is significantly shorter ( $\leq 20$ minutes) than NT-proBNP (60-120 minutes) and is removed from circulation by a receptor-mediated mechanism and degradation by neutral endopeptidases. The NT-proBNP assays detect NT-proBNP and proBNP.

Normal circulating levels of BNP and NT-proBNP are very low whereas there is a significant rise in HF. BNP levels of $>100 \mathrm{pg} / \mathrm{mL}$ diagnosed HF with an accuracy of 85\% in "the breathing not multinational study." 11 Similarly NT-proBNP levels > $900 \mathrm{pg} / \mathrm{mL}$ in the PRIDE (N-terminal Pro-BNP Investigation of Dyspnea in the Emergency department) study became the strongest predictor of HF than other forms of assessment. ${ }^{12}$ NT-proBNP has stratified cutoff points about age $(<50$ years $=\geq 450 \mathrm{pg} / \mathrm{mL} ; 50-75$ years $=\geq 900 \mathrm{pg} / \mathrm{mL}$; $>75$ years $=\geq 1,800 \mathrm{pg} / \mathrm{mL}$ ), which are reliable and accurate in prediction of HF. Both of these markers are very crucial in cases of indecision and can exclude the diagnosis or "rule out" if the values are low. ${ }^{13}$

Many other cardiopulmonary disorders, other than HF, also present with increased levels of BNP or NT-proBNP, and lower values are seen in obesity. Yet the age-wise cutoff values for NT-proBNP still have high diagnostic accuracy with specificity of $90 \%$, a positive predictive value (PPV) of $85 \%$, and a negative predictive value (NPV) of $95 \%$ in obese patients as well. ${ }^{14}$

\section{Inflammatory and Prognostic Markers C-Reactive Protein}

An acute phase protein synthesized by the liver, C-reactive protein (CRP) is mostly stimulated by the cytokine, interleukin (IL)-6. CRP levels are thought to differ by sex and ethnicity and increase in acute illness. CRP levels $>10 \mathrm{mg} / \mathrm{L}$ indicate an acute illness, whereas a value $>3 \mathrm{mg} /$ L indicates an increased risk, 1 to $3 \mathrm{mg} / \mathrm{L}$ a moderate risk, and < $1 \mathrm{mg} / \mathrm{L}$ shows low risk. CRP levels increase in several other conditions and are hence a predictor of prognosis and extent of disease as suggested by the PROVE-IT PRavastatin Or AtorVastatin Evaluation and 
Infection Therapy Trial studies. ${ }^{15}$ The improved high sensitive CRP assays are widely used for risk assessment.

\section{Homocysteine}

An intermediary amino acid, homocysteine is an independent risk factor for the development of atherosclerosis. About 5 to $7 \%$ of the general population has moderate hyperhomocysteinemia, which may be a result of vitamin deficiencies that can be successfully treated or genetic disorders. Hyperhomocysteinemia causes intimal thickening, disruption of the elastic lamina, smooth muscle hypertrophy, and platelet aggregation, and hence is directly implicated in vascular injury. It is therefore useful marker for risk assessment, and regular assays are available for the same.

\section{Soluble CD40 ligand (sCD40L)}

It is another inflammatory marker, a signaling protein that reflects both inflammation and platelet interaction with the plaque and is found increased in ACS. ${ }^{16}$ However, often it has been of use in prognostication rather than diagnosis. Also, assays are cumbersome and not adaptable for diagnosis. Several biomarkers that are used currently and in the past decade are listed as follows.

\section{Lipoprotein-Associated Phospholipase A2 (Lp-PLA2)}

Also called platelet-activating factor, is synthesized by lymphocytes and monocytes and produces highly atherogenic lipid fragments that cause endothelial adhesion. It is mostly used as a research tool and in risk stratification.

\section{Myeloperoxidase}

It is a degranulation product of the white blood cells (WBCs) and is elevated in the blood vessels where a plaque is present and found to be increased in coronary artery disease and ACS. ${ }^{14}$ Systemic levels again are most often useful in prognostication, in patients who arrive with chest pain. Commercial assays are available for myeloperoxidase, but types of specimen collected have shown variation.

\section{Pregnancy-Associated Plasma Protein A (PAPP-A)}

This protein is a metalloproteinase and a member of the insulin-like growth factor family of proteins. Elevated levels are indicative of an ongoing neovascularization process in the coronary arteries and an incipient plaque rupture. However, there is no established correlation with available markers; rather, it is an indicator of adverse $\mathrm{CV}$ events and not used routinely. ${ }^{16}$

\section{Choline}

It is released from phospholipids on cleavage and is suggested to indicate necrosis and ischemia. Again, it has been considered to be of value in prognostication. ${ }^{16}$

\section{Soluble Suppression of Tumorigenicity 2 (sST2)}

It is member of IL-1 family and is believed to play a role in the cardiac remodeling and signal inflammation by its interaction with IL-33. The gene is induced strongly by the stretch of a cardiomyocyte or cardiac fibroblast. ${ }^{17}$ Serum ST2 levels are not affected by age, renal function, or body mass index (BMI), as BNP or NT-proBNP and increasing concentrations ( $>35 \mathrm{ng} / \mathrm{mL}$ ) are indicative of adverse clinical outcome in HF. In AHF patients, regardless of left ventricular ejection fraction, ST2 was found to be an independent and additive predictor of bad prognosis. In chronic HF, its ability to predict adverse events was similar to NT-proBNP, but it is advised to use a multimarker strategy to improve predictive ability. When combined with hsTn and NT-proBNP in patients with AHF, SST2 added to the risk of death with an HR of $2.64 .{ }^{18}$ In a healthy population and in AMI, elevated ST2 was useful to predict development of HF. ${ }^{19,20}$

\section{Galectin 3}

This is a member of the protein lectin family that has a specific binding site for $\beta$-galactosides, which is a carbohydrate recognition-binding domain. For over a decade, galectin 3 has been implicated in fibrogenesis, myofibroblast proliferation, ventricular remodeling, and inflammation. Though it is elevated in acute or chronic HF, when adjusted for renal function or other markers, it loses its prognostic meaning. ${ }^{21}$

\section{MicroRNAs (miRNAs)}

These are the long noncoding RNAs that inhibit gene expression by binding to sites in the untranslated regions of targeted messenger RNAs and are known to be involved in every biological process. ${ }^{22}$ Being very stable molecules and tissue specific, they can be detected in circulation. Four groups of miRNAs are identified, which are involved in regulation of the CV system of which nearly 18 seem specific for AMI, for example miR-155, miR-34a, miR-126, miR-133a, miR-208b, and a few others show much promise as specific and accurate markers of dysfunction. ${ }^{23}$

\section{Midregional Proadrenomedullin (MR-proADM)}

In response to the cardiac dysfunction, which is a precursor of adrenomedullin, a vasodilator, synthesized from the adrenal medulla, is released. It is elevated in HF both acute and chronic and is useful in prediction of hospitalization and mortality. ${ }^{24}$

\section{Copeptin}

This is a marker in sepsis, which has been tried as an early biomarker for AMI with cardiac troponin, but much validation needs to be done. Copeptin is a stable C-terminal pro-peptide fragment of arginine vasopressin (AVP) and regulates the free water clearance and plasma osmolality by regulating absorption of water from the kidneys. Again among the biomarkers in the BACH (Biomarkers in Acute Heart Failure) trial, ${ }^{25}$ elevated copeptin level strongly predicted mortality even after adjusting for NT-proBNP and other traditional variables.

\section{Conclusion}

There is no single marker for ACS, though as an immediate bedside test, CTnT/I is widely used along with clinical signs of 
ACS and ECG and is one of the most successful diagnostic tests developed thus far. Measurement of hs-CRP, NT-proBNP in addition to cTns, may be useful in risk assessment in patients with clinical symptoms of ACS. A multimarker approach, consisting of two or more pathologically diverse markers, which necessarily includes cardiac troponins, enhances risk stratification in patients of ACS.

For the diagnosis and prognosis of HF, as per the American college of Cardiology foundation/American Heart Association HF guidelines, BNP and NT-proBNP form the class I recommendation and for guiding HF management, they form the class IIa recommendation in out-patients with chronic $\mathrm{HF}^{26}$ Additionally, $\mathrm{TnT} / \mathrm{TnI}$ are class I recommendation for prognosis and detection of AMI. Biomarkers of myocardial fibrosis (sST2 and galectin 3) have class IIb recommendation for chronic and acute HF.

Use of a personalized precision approach, as seen in other areas of medicine, with different biomarkers, including "miRNAs" shows great promise and is gaining momentum in cardiac disease.

\section{Conflict of Interest}

None.

\section{Acknowledgment}

I would like to acknowledge funding from the National Institute of Health (NIH) R01 Grant HL136232 to MK.

\section{References}

1 Amsterdam EA, Wenger NK, Brindis RG, et al. AHA/ACC guideline for the management of patients with non-ST elevation acute coronary syndrome: executive summary. Circulation 2014;130(5):2354-2394

2 Savonitto S, Granger CB, Ardissino D, et al; GUSTO-IIb Investigators. The prognostic value of creatine kinase elevations extends across the whole spectrum of acute coronary syndromes. J Am Coll Cardiol 2002;39(1):22-29

3 Bernstein L. Cardiac-Related Creatine Kinase Isoenzyme MB. Pathology Outlines 2017

4 Sharma S, Jackson PG, Makan J. Cardiac troponins. J Clin Pathol 2004;57(10):1025-1026

5 Gaggin HK, Januzzi JL Jr. Cardiac biomarkers and heart failure. Am College Cardiol 2015. Available at https://www.acc.org/ latest-in-Cardiology/\%20articles/\%202015/\%2002/09/13/00/ cardiac-biomarkers-and-heart-failure

6 Peacock WF, Baumann BM, Bruton D, et al. Efficacy of high-sensitivity troponin $\mathrm{T}$ in identifying very-low-risk patients with possible acute coronary syndrome. JAMA Cardiol 2018;3(2):104-111

7 Westermann D, Neumann JT, Sörensen NA, Blankenberg S. High-sensitivity assays for troponin in patients with cardiac disease. Nat Rev Cardiol 2017;14(8):472-483

8 Xue Y, Clopton P, Peacock WF, Maisel AS. Serial changes in high-sensitive troponin I predict outcome in patients with decompensated heart failure. Eur J Heart Fail 2011;13(37):C42

9 Bhakthavatsala Reddy C, Cyriac C, Desle HB. Role of "ischemia modified albumin" (IMA) in acute coronary syndromes. Indian Heart J 2014;66(6):656-662

10 Das UN. Heart-type fatty acid-binding protein (H-FABP) and coronary heart disease. Indian Heart J 2016;68(1):16-18
11 Maisel AS, Krishnaswamy P, Nowak RM, et al; Breathing Not Properly Multinational Study Investigators. Rapid measurement of B-type natriuretic peptide in the emergency diagnosis of heart failure. N Engl J Med 2002;347(3):161-167

12 Januzzi JL Jr, Camargo CA, Anwaruddin S, et al. The N-terminal pro-BNP investigation of dyspnea in the emergency department (PRIDE) study. Am J Cardiol 2005;95(8):948-954

13 Ahmad T, Fiuzat M, Pencina MJ, et al. Charting a roadmap for heart failure biomarker studies. JACC Heart Fail 2014;2(5):477-488

14 Niederkofler EE, Kiernan UA, O'Rear J, et al. Detection of endogenous B-type natriuretic peptide at very low concentrations in patients with heart failure. Circ Heart Fail 2008;1(4):258-264

15 Ridker PM, Cannon CP, Morrow D, et al; Pravastatin or Atorvastatin Evaluation and Infection Therapy-Thrombolysis in Myocardial Infarction 22 (PROVE IT-TIMI 22) Investigators. C-reactive protein levels and outcomes after statin therapy. N Engl J Med 2005;352(1):20-28

16 Apple FS, Wu AH, Mair J, et al; Committee on Standardization of Markers of Cardiac Damage of the IFCC. Future biomarkers for detection of ischemia and risk stratification in acute coronary syndrome. Clin Chem 2005;51(5):810-824

17 Sanada S, Hakuno D, Higgins LJ, Schreiter ER, McKenzie AN, Lee RT. IL-33 and ST2 comprise a critical biomechanically induced and cardioprotective signaling system. J Clin Invest 2007;117(6):1538-1549

18 Pascual-Figal DA, Manzano-Fernández S, Boronat M, et al. Soluble ST2, high-sensitivity troponin $\mathrm{T}$ - and N-terminal pro-B-type natriuretic peptide: complementary role for risk stratification in acutely decompensated heart failure. Eur J Heart Fail 2011;13(7):718-725

19 KohliP,BonacaMP,KakkarR, etal. Role ofST2 in non-ST-elevation acute coronary syndrome in the MERLIN-TIMI 36 trial. Clin Chem 2012;58(1):257-266

20 Wang TJ, Wollert KC, Larson MG, et al. Prognostic utility of novel biomarkers of cardiovascular stress: the Framingham Heart Study. Circulation 2012;126(13):1596-1604

21 Lok DJ, Van Der Meer P, de la Porte PW, et al. Prognostic value of galectin-3, a novel marker of fibrosis, in patients with chronic heart failure: data from the DEAL-HF study. Clin Res Cardiol 2010;99(5):323-328

22 Elnakish MT, Kuppusamy P, Khan M. Stem cell transplantation as a therapy for cardiac fibrosis. J Pathol 2013;229(2):347-354

23 Zhu Y, Lin Y, Yan W, et al. Novel biomarker microRNAs for subtyping of acute coronary syndrome: a bioinformatics approach. BioMed Res Int 2016;2016:4618323

24 Maisel A, Mueller C, Nowak R, et al. Mid-region pro-hormone markers for diagnosis and prognosis in acute dyspnea: results from the BACH (Biomarkers in Acute Heart Failure) trial. J Am Coll Cardiol 2010;55(19):2062-2076

25 Maisel A, Xue Y, Shah K, et al. Increased 90-day mortality in patients with acute heart failure with elevated copeptin: secondary results from the Biomarkers in Acute Heart Failure (BACH) study. Circ Heart Fail 2011;4(5):613-620

26 Yancy CW, Jessup M, Bozkurt B, et al; American College of Cardiology Foundation; American Heart Association Task Force on Practice Guidelines. 2013 ACCF/AHA guideline for the management of heart failure: a report of the American College of Cardiology Foundation/American Heart Association Task Force on Practice Guidelines. J Am Coll Cardiol 2013;62(16):e147-e239 